BAHTERASIA 1 (1) (2020)

Bahterasia: Jurnal Ilmiah Pendidikan Bahasa dan Sastra Indonesia

http://journal.umsu.ac.id/sju/index.php/bahterasia

\title{
EKSPERIMENTASI MODEL PEMBELAJARAN WORD SQUARE PADA MATA KULIAH MENGIDENTIFIKASI JENIS-JENIS PUISI DARI HASIL BELAJAR MAHASISWA PENDIDIKAN BAHASA DAN SASTRA INDO-NESIA FKIP UMSU
}

\author{
Winarti $^{\bowtie}$ dan Sri Listiana Izar
}

Prodi Pendidikan Bahasa dan Sastra Indonesia, Fakultas Keguruan dan Ilmu Pendidikan, Universitas Muhammadiyah Sumatera Utara, Indonesia

\begin{abstract}
Info Artikel Abstrak
Sejarah Artikel:

Oktober 2019

Disetujui

Desember 2019

Dipublikasikan

Februari 2020

Banyaknya jenis-jenis puisi akan dapat membuat mahasiswa sulit mengindentifikasi, apalagi jika materi disampaikan secara konvensional, maka bisa jadi hasil dari pembelajaran tidak akan meninggalkan kesan yang menyenangkan dan nilai yang memuaskan. Padahal puisi adalah bagian dari materi di program studi pendidikan bahasa dan sastra Indonesia yang wajib untuk dipahami dan dikuasai agar mahasiswa kelak dapat menyebarkan ilmu sastra pada generasi berikutnya. Selain itu mahasiswa sering terbalik membagi-baginya dan ironisnya, mereka tidak menganggap bahwa pembagian puisi ini penting sehingga tidak benar-benar mempelajarinya, padahal setiap Ujian Nasional (UN) soal mengenai pembagian puisi ini selalu menjadi pilihan untuk dikeluarkan oleh tim penyusun soal Ujian Nasional (UN). Melalui model pembelajaran word square akan muncul sebuah pembelajaran di kelas yang bermanfaat dan dikemas dengan suasana yang menyenangkan karena model pembelajaran ini memiliki sistem kerja yang mirip teka-teki silang. Dengan metode mendatar dan menurunnya dapat membuat mahasiswa belajar sambil bermain, sehingga dapat memengaruhi hasil dari proses pembelajaran mengidentifikasi jenis-jenis puisi. Mahasiswa lebih cepat menangkap materi, lebih cepat mengingat, dan materi jenis-jenis puisi dapat berkesan di benak mereka.
\end{abstract}

Kata kunci: model pembelajaran word square, jenis-jenis puisi

\begin{abstract}
The number of types of poetry can make students difficult to identify, especially if the material is delivered conventionally, then the results of learning will not leave a pleasant impression and satisfactory value. Though poetry is part of the material in the Indonesian language and literary education study program that must be understood and mastered so that students can later spread literature in the next generation. Besides that, students are often turned upside down and ironically, they do not consider that the distribution of poetry is important so that they do not really study it, even though each National Examination (UN) questions regarding the distribution of poetry are always an option to be issued by the drafting team on the National Examination (UN). Through the word square learning model a learning class will emerge that is useful and packed with a pleasant atmosphere because this learning model has a work system that is similar to crossword puzzles. With the horizontal and decreasing method, it can make students learn while playing, so that it can affect the results of the learning process to identify types of poetry. Students catch material faster, remember faster, and material types of poetry can impress on their minds.
\end{abstract}

Keywords: word square learning model, types of poetry

(C) 2020 Universitas Muhammadiyah Sumatera Utara
p-ISSN $x x x x-x x x x$

e-ISSN $x x x x-x x x x$

Kampus UMSU Jalan Kapten Muchtar Basri No 3,

Medan-Sumatera Utara, 20238

e-mail: jurnalbahterasia@umsu.ac.id. 


\section{PENDAHULUAN}

Sastra memiliki beberapa bentuk yaitu drama, prosa fiksi, dan puisi. Setiap bentuk ini mempunyai pembagiannya lagi. Puisi misalnya, memiliki pembagian yaitu puisi lama, puisi baru, dan puisi modern. Pada setiap pembagian ini mempunyai pembagian lagi seperti pada puisi lama pembagiannya yaitu mantra, pantun, gurindam, syair, dan talibun. Puisi baru seperti distikon, terzina, kuint, sektet, septima, soneta, dan lain sebagainya. Begitupun dengan puisi modern. Namun sayang, mahasiswa saat ini tidak memahami pembagian ini.

Mereka sering terbalik membagi-baginya dan ironisnya, mereka tidak menganggap bahwa pembagian ini penting sehingga tidak benar-benar mempelajarinya, padahal setiap Ujian Nasional (UN) soal mengenai pembagian puisi ini selalu menjadi pilihan untuk dikeluarkan oleh tim penyusun soal Ujian Nasional (UN). Penyebab lain muncul karena cara menyampaikan materi dari guru-guru mereka terdahulu bisa jadi memang tidak efektif. Guru mereka di masa sekolah menengah mungkin masih memakai cara yang konvensional, sehingga berdampak pada kemampuan mereka dalam menentukan jenisjenis puisi hingga saat ini.

Sebagai calon pengajar yang kelak akan mendidik para peserta didik, maka mahasiswa sejak dini harus dibekali dengan berbagai ilmu. Salah satunya materi mengenai pembagian jenis puisi ini tidak boleh diabaikan begitu saja karena akan tetap muncul di berbagai kesempatan soal ujian, lomba, atau kompetisi yang lain.

Untuk itulah, peneliti mencoba mengambil sebuah penelitian mengenai fenomena ini yang akan dikolaborasikan dengan sebuah model pembelajaran. Seperti yang disampaikan oleh Yamin (dalam Nurjannah, 2015: 1), "Model pembelajaran adalah suatu pola metodologi untuk melaksanakan perubahan, sedangkan pembelajar adalah seorang profesionalis yang menjalankan fungsi-fungsinya dengan menggunakan metodologi untuk membelajarkan peserta didik dengan cara yang tidak konstan, artinya pembelajar harus berinovasi dan menciptakan perubahan yang baik pada dirinya ataupun pada peserta didik." Peneliti ingin memberikan perubahan meskipun belum tahu hasil perubahan itu seperti apa namun tidak ada salahnya melakukan inovasi dari waktu ke waktu, sehingga peneliti memilih sebuah metode pembelajaran yaitu word square.

Penelitian ini mengambil judul “Eksperimentasi Model Pembelajaran Word Square pada Mata Kuliah Mengidentifikasi Jenis-jenis Puisi dari Hasil Belajar Mahasiswa Pendidikan Bahasa dan Sastra Indonesia FKIP UMSU".

\section{METODE PENELITIAN}

Penelitian ini menggunakan metode eksperimen dengan desain two-group post-test only desaign. Desain penelitian ini bertujuan untuk memperlihatkan perbedaan pencapaian antara kelompok eksperimen dan pencapaian kelompok kontrol.

Adapun aspek penelitian kemampuan me-nentukan jenis-jenis puisi tersebut adalah sebagai berikut: 
Tabel 1

Aspek Penilaian Mengidentifikasi Jenis-jenis Puisi

\begin{tabular}{|c|c|c|c|}
\hline No. & $\begin{array}{l}\text { Aspek yang } \\
\text { Dinilai }\end{array}$ & Indikator Penilaian & Skor \\
\hline \multirow[t]{3}{*}{1} & Puisi lama & $\begin{array}{l}\text { a. Mahasiswa mampu mengidentifikasi jenis-jenis puisi } \\
\text { lama }\end{array}$ & 3 \\
\hline & & $\begin{array}{l}\text { b. Mahasiswa kurang mampu mengidentifikasi jenis- } \\
\text { jenis puisi lama }\end{array}$ & 2 \\
\hline & & $\begin{array}{l}\text { c. Mahasiswa tidak mampu mengidentifikasi jenis-jenis } \\
\text { puisi lama }\end{array}$ & 1 \\
\hline \multirow[t]{3}{*}{2} & Puisi baru & $\begin{array}{l}\text { a. Mahasiswa mampu mengidentifikasi jenis-jenis puisi } \\
\text { baru }\end{array}$ & 3 \\
\hline & & $\begin{array}{l}\text { b. Mahasiswa kurang mampu mengidentifikasi jenis- } \\
\text { jenis puisi baru }\end{array}$ & 2 \\
\hline & & $\begin{array}{l}\text { c. Mahasiswa tidak mampu mengidentifikasi jenis-jenis } \\
\text { puisi baru }\end{array}$ & 1 \\
\hline \multirow[t]{3}{*}{3} & Puisi modern & $\begin{array}{l}\text { a. Mahasiswa mampu mengidentifikasi jenis-jenis puisi } \\
\text { modern }\end{array}$ & 3 \\
\hline & & $\begin{array}{l}\text { b. Mahasiswa kurang mampu mengidentifikasi jenis- } \\
\text { jenis puisi modern }\end{array}$ & 2 \\
\hline & & $\begin{array}{l}\text { c. Mahasiswa tidak mampu mengidentifikasi jenis-jenis } \\
\text { puisi modern }\end{array}$ & 1 \\
\hline \multicolumn{2}{|c|}{ Total skor } & & 9 \\
\hline
\end{tabular}

\section{HASIL PENELITIAN DAN PEMBAHASAN}

\section{Hasil Penelitian}

Sebagaimana telah dikemukakan dalam instrumen penelitian bahwa alat yang digunakan dalam penelitian, peneliti menggunakan tes yaitu tes kemampuan mengidentifikasi jenis-jenis puisi. Setelah melaksanakan penyebaran tes kepada 32 mahasiswa, dapatlah diketahui nilai kemampuan mengidentifikasi jenis-jenis puisi dengan menggunakan model pembelajaran word square oleh mahasiswa semester III Program Studi Pendidikan Bahasa dan Sastra Indonesia FKIP UMSU tahun akademik 2017-2018. Selanjutnya hasil tes tersebut diolah menjadi beberapa tahap.

Berdasarkan hasil tes yang telah diperiksa maka nilai yang diperoleh disajikan dalam bentuk tabel.

Tabel 2

Skor Mentah Kemampuan Mengidentifikasi Jenis-jenis Puisi pada Kelas Eksperimen

\begin{tabular}{clccccccc}
\hline \multirow{2}{*}{ No } & \multicolumn{3}{c}{ Nama } & \multicolumn{3}{c}{ Mendatar } & \multicolumn{3}{c}{ Menurun } & \multirow{2}{*}{ Skor } \\
\cline { 3 - 7 } & & $\mathbf{1}$ & $\mathbf{2}$ & $\mathbf{3}$ & $\mathbf{1}$ & $\mathbf{2}$ & $\mathbf{3}$ & \\
\hline 1 & Indah Mayangsari & 1.5 & 1.5 & 1.5 & 1.5 & 1.5 & 1.5 & $\mathbf{9}$ \\
2 & Nur Islamia & 1.5 & 1.5 & 1.5 & 1.5 & 1.5 & 1.5 & $\mathbf{9}$ \\
3 & Syarifah Aini & 1.5 & 1.5 & 1.5 & 1.5 & 1.5 & 1.5 & $\mathbf{9}$ \\
4 & Diana Sari & 1.5 & 1.5 & 1.5 & 1.5 & 1.5 & 1.5 & $\mathbf{9}$ \\
5 & Lidia Herlina Siregar & 1.5 & 1.5 & 1.5 & 1.5 & 1.5 & 1.5 & $\mathbf{9}$ \\
6 & Feni Hardianti & 1.5 & 1.5 & 1.5 & 1.5 & 1.5 & 1.5 & $\mathbf{9}$ \\
7 & Ladia Ummi & 1.5 & 1.5 & 1.5 & 1.5 & 1.5 & 1.5 & $\mathbf{9}$ \\
8 & Wardah Tul Jannah & 1.5 & 1.5 & 1.5 & 1.5 & 1.5 & 1.5 & $\mathbf{9}$ \\
9 & Dewi Yulisa Putri & 1.5 & 1.5 & 1.5 & 1.5 & 1.5 & 1.5 & $\mathbf{9}$ \\
10 & Lili Anriani & 1.5 & 1.5 & 1.5 & 1.5 & 1.5 & 1.5 & $\mathbf{9}$ \\
11 & Resinta Widyanti & 1.5 & 1.5 & 1.5 & 1.5 & 1.5 & 1.5 & $\mathbf{9}$ \\
\hline
\end{tabular}




\begin{tabular}{|c|c|c|c|c|c|c|c|c|}
\hline 12 & Sri Rahayu & 1.5 & 1.5 & 1.5 & 1.5 & 1.5 & 1.5 & 9 \\
\hline 13 & Meilani Ulfa S. & 1.5 & 1.5 & 1.5 & 1.5 & 1.5 & 1.5 & 9 \\
\hline 14 & Rani Sulistriana & 1.5 & 1.5 & 1.5 & 1.5 & 1.5 & 1.5 & 9 \\
\hline 15 & Lailan Syahfitri & 1.5 & 1.5 & 1.5 & 1.5 & 1.5 & 1.5 & 9 \\
\hline 16 & Nia Risana & 1.5 & 1.5 & 1.5 & 1.5 & 1.5 & 1.5 & 9 \\
\hline 17 & Ahmad Rinaldy & 1.5 & 1.5 & 1.5 & 1.5 & 1.5 & 1.5 & 9 \\
\hline 18 & Afiva Zahra Simanjuntak & 1.5 & 1.5 & 1.5 & 1.5 & 1.5 & 1.5 & 9 \\
\hline 19 & Izmawal Pebriani Nst. & 1.5 & 1.5 & 1.5 & 1.5 & 1.5 & 1.5 & 9 \\
\hline 20 & Irma Syahfitri & 1.5 & 1.5 & 1.5 & 1.5 & 1.5 & 1.5 & 9 \\
\hline 21 & Rizky Ratna Dani & 1.5 & 1.5 & 1.5 & 1.5 & 1.5 & 1.5 & 9 \\
\hline 22 & Sintia & 1.5 & 1.5 & 1.5 & 1.5 & 1.5 & 1.5 & 9 \\
\hline 23 & Windiani Siregar & 1.5 & 1.5 & 1.5 & 1.5 & 1.5 & 1.5 & 9 \\
\hline 24 & Anggi Apriani Nst. & 1.5 & 1.5 & 1.5 & 1.5 & 1.5 & 1.5 & 9 \\
\hline 25 & Dewi Yuliana S. & 1.5 & 1.5 & 1.5 & 1.5 & 1.5 & 1.5 & 9 \\
\hline 26 & Winda Apriska & 1.5 & 1.5 & 1.5 & 1.5 & 1.5 & 1.5 & 9 \\
\hline 27 & Zainda Savira Siregar & 1.5 & 1 & 1.5 & 1.5 & 1.5 & 1.5 & 8.5 \\
\hline 28 & Juhrina & 1.5 & 1 & 1.5 & 1.5 & 1.5 & 1.5 & 8.5 \\
\hline 29 & Hermawan & 1.5 & 1.5 & 1.5 & 1.5 & 1.5 & 1.5 & 9 \\
\hline 30 & Endha Putri R. Hsb. & 1.5 & 1.5 & 1.5 & 1 & 1.5 & 1.5 & 8.5 \\
\hline 31 & Dwi Ayu Monica & 1.5 & 1.5 & 1 & 1 & 1.5 & 1 & 7.5 \\
\hline \multirow[t]{2}{*}{32} & Riana Dewi & 1.5 & 1.5 & 1.5 & 1 & 1.5 & 1.5 & 8.5 \\
\hline & Total & & & & & & & 284.5 \\
\hline
\end{tabular}

Tabel di atas menunjukkan daftar skor mentah kemampuan mahasiswa mengiden-tifikasi jenis-jenis puisi pada kelas eksperimen dengan menggunakan model pembelajaran word square. Sementara berikut ini adalah tabel skor mentah kemampuan mengidentifikasi jenis-jenis puisi pada kelas kontrol.

Tabel 3

Skor Mentah Kemampuan Mengidentifikasi Jenis-jenis Puisi pada Kelas Kontrol

\begin{tabular}{clccccccc}
\hline No & \multicolumn{1}{c}{ Nama } & $\mathbf{1}$ & $\mathbf{2}$ & $\mathbf{3}$ & $\mathbf{4}$ & $\mathbf{5}$ & $\mathbf{6}$ & Skor \\
\hline 1 & RizkiAldea & 1,5 & 0,5 & 1,5 & 0,5 & 1.5 & 0,5 & $\mathbf{6}$ \\
2 & Ricci Novita Sari & 1,5 & 0,5 & 1,5 & 0,5 & 1,5 & 0,5 & $\mathbf{6}$ \\
3 & PrinsellaBalqisLubis & 1,5 & 0,5 & 1,5 & 1,5 & 1,5 & 1 & $\mathbf{7 , 5}$ \\
4 & MeriSusanti & 1,5 & 1,5 & 1,5 & 1,5 & 1,5 & 1 & $\mathbf{8 , 5}$ \\
5 & May Sarah Silitonga & 1,5 & 1,5 & 1,5 & 0,5 & 1,5 & 1 & $\mathbf{7 , 5}$ \\
6 & BungaSrivlinaSembiring & 1,5 & 1,5 & 1,5 & 1,5 & 1,5 & 1 & $\mathbf{8 , 5}$ \\
7 & Mira Ulfa & 1,5 & 1,5 & 1,5 & 1,5 & 1,5 & 1 & $\mathbf{8 , 5}$ \\
8 & Wanda Ivo Sunestri & 1,5 & 1,5 & 1,5 & 1,5 & 1,5 & 1 & $\mathbf{8 , 5}$ \\
9 & DesiRatnasari & 1,5 & 1,5 & 1,5 & 1,5 & 1,5 & 1 & $\mathbf{8 , 5}$ \\
10 & YenniOktaviani Br Sinulingga & 1,5 & 1,5 & 1,5 & 1,5 & 1,5 & 1 & $\mathbf{8 , 5}$ \\
11 & Winda Sri Anolia & 1,5 & 1,5 & 1,5 & 0,5 & 1,5 & 1 & $\mathbf{7 , 5}$ \\
12 & CiciWinda Sari & 1,5 & 1,5 & 1,5 & 0,5 & 1,5 & 1 & $\mathbf{7 , 5}$ \\
13 & Ade Elpriyanti & 1,5 & 1,5 & 1,5 & 0,5 & 1,5 & 0,5 & $\mathbf{7}$ \\
14 & DesiSalvira & 0,5 & 1,5 & 0,5 & 0,5 & 1,5 & 0,5 & $\mathbf{5}$ \\
15 & SitiHardiyantiAlawiyah & 0,5 & 1,5 & 0,5 & 0,5 & 1,5 & 0,5 & $\mathbf{5}$ \\
16 & Lia Pertiwi & 1,5 & 1,5 & 0,5 & 0,5 & 1,5 & 0,5 & $\mathbf{6}$ \\
17 & NurulHayati & 1,5 & 1,5 & 1,5 & 0,5 & 1,5 & 0,5 & $\mathbf{7}$ \\
18 & RevinaNovianti & 1,5 & 1,5 & 1,5 & 0,5 & 1,5 & 0,5 & $\mathbf{7}$ \\
19 & Diah Karina Sinamo & 1,5 & 1,5 & 1,5 & 0,5 & 1,5 & 0,5 & $\mathbf{7}$ \\
20 & DewiNurhalimah & 1,5 & 1,5 & 0,5 & 0,5 & 1,5 & 1 & $\mathbf{6 , 5}$ \\
21 & ErniYusnitaAruan & 1,5 & 1,5 & 0,5 & 0,5 & 1,5 & 1 & $\mathbf{6 , 5}$ \\
22 & NurazijahHsrahap & 1,5 & 1,5 & 0,5 & 0,5 & 1,5 & 1 & $\mathbf{6 , 5}$ \\
23 & Putri Sari Dewi & 1,5 & 1,5 & 0,5 & 0,5 & 1,5 & 1 & $\mathbf{6 , 5}$ \\
24 & Eva JuliYarti & 1,5 & 1,5 & 1,5 & 0,5 & 1,5 & 0,5 & $\mathbf{7}$ \\
25 & Mia Nazwi & 1,5 & 1,5 & 0,5 & 0,5 & 1,5 & 0,5 & $\mathbf{6}$ \\
26 & Pujiarti & 1,5 & 0,5 & 0,5 & 0,5 & 1,5 & 0,5 & $\mathbf{5}$ \\
27 & Nurlaila Sari & 1,5 & 1,5 & 1,5 & 1,5 & 1,5 & 1 & $\mathbf{8 , 5}$ \\
28 & SitiFadilahAini & 1,5 & 1,5 & 1,5 & 0,5 & 1,5 & 1 & $\mathbf{7 , 5}$ \\
29 & Nurisnani & 1,5 & 1,5 & 1,5 & 0,5 & 1,5 & 1 & $\mathbf{7 , 5}$ \\
30 & Kartiyana Sam & 1,5 & 1,5 & 1,5 & 1,5 & 1,5 & 1 & $\mathbf{8 , 5}$ \\
31 & Nadia Imelda Br Ginting & 1,5 & 1,5 & 1,5 & 1,5 & 1,5 & 1 & $\mathbf{8 , 5}$
\end{tabular}




\begin{tabular}{|c|c|c|c|c|c|c|c|c|}
\hline 32 & KhusnulHaizhan & 1,5 & 0,5 & 1,5 & 0,5 & 1,5 & 0,5 & 6 \\
\hline 33 & ZaharaZaitiraNasution & 1,5 & 1,5 & 1,5 & 1,5 & 1,5 & 1 & 8,5 \\
\hline & Total & & & & & & & 236 \\
\hline
\end{tabular}

Tabel di atas menunjukkan daftar nilai yang diperoleh kelas kontrol terhadap kemampuan mengidentifikasi Jenis-jenis puisi dengan menggunakan model konvensional.

Keterangan Tabel :
1. Puisi lama
2. Puisi baru
3. Puisi modern
4. Puisi lama
5. Puisi baru
6. Puisi modern

Tabel 4

Kategori Nilai Mahasiswa Kelas Eksperimen

\begin{tabular}{ccccc}
\hline No. & Rentang Nilai & Kategori & Jumlah & Persentase \\
\hline 1. & $80-100$ & Sangat Baik & 32 & $100 \%$ \\
2. & $66-79$ & Baik & - & - \\
3. & $56-65$ & Cukup & - & - \\
4. & $40-55$ & Kurang & - & - \\
5. & $<39$ & Gagal & - & - \\
\hline \multicolumn{2}{c}{ Total } & & $\mathbf{3 2}$ & $\mathbf{1 0 0 \%}$ \\
\multicolumn{2}{c}{ Nilai Rata-rata } & & $\mathbf{9 8 . 7 8}$ & Sangat baik \\
\hline
\end{tabular}

Tabel 5

Kategori Nilai Mahasiswa Kelas Kontrol

\begin{tabular}{ccccc}
\multicolumn{5}{c}{ Kategori Nilai Mahasiswa Kelas Kontrol } \\
\hline No. & Rentang Nilai & Kategori & Jumlah & Persentase \\
1. & $80-100$ & Sangat Baik & 16 & $48.48 \%$ \\
2. & $66-79$ & Baik & 14 & $42.42 \%$ \\
3. & $56-65$ & Cukup & 3 & $9.09 \%$ \\
4. & $40-55$ & Kurang & - & - \\
5. & $<39$ & Gagal & - & - \\
\hline \multicolumn{7}{r}{ Total } & & 33 & $100 \%$ \\
& Rata - rata & & $\mathbf{7 9 . 4 5}$ & Baik \\
\hline
\end{tabular}

Berdasarkan penghitungan rata-rata nilai dan standar deviasi masing-masing kelas eksperimen dan kontrol, maka dapat disimpulkan bahwa hasil penelitian ini memiliki kecendrungan terhadap variabel penelitian. Variabel penelitian ini bertujuan untuk mengetahui pengaruh model pembelajaran word square terhadap kemampuan mengidentifikasi jenis-jenis puisi oleh mahasiswa semester III program studi pendidikan Bahasa dan Sastra Indonesia FKIP UMSU tahun akademik 2017-2018. Hal ini dapat dilihat dari besarnya nilai rata-rata yang diperoleh pada kelas eksperimen jika dibandingkan dengan kelas kontrol yaitu (98.78>79.45) sehingga dapat disimpulkan secara garis besar bahwa terdapat pengaruh penggunaan model pembelajaran word square terhadap kemampuan mengidentifikasi jenis-jenis puisi oleh mahasiswa.

Berdasarkan hasil tes yang telah diberikan kepada mahasiswa, diperoleh bahwa jumlah nilai variabel X1 atau yang diajarkan dengan model word square lebih tinggi dibandingkan jumlah nilai variabel $\mathrm{X} 2$ yang diajarkan dengan menggunakan model konvensional.

\section{Pembahasan Hasil Penelitian}

Dari hasil penelitian di atas, terbukti bahwa "Ada pengaruh penggunaan model pembelajaran word square terhadap kemampuan mengidentifikasi jenis-jenis puisi oleh 
mhasiswa semester III program studi pendidikan bahasa dan sastra Indonesia FKIP UMSU tahun akademik 2017-2018. Hal ini dibuktikan berdasarkan perhitungan diketahui kemampuan mengidentifikasi jenis-jenis puisi yang diajar dengan menggunakan model pembelajaran word square mahasiswa paling banyak mendapat nilai 80-100 yaitu sebesar $100 \%$ artinya kemampuan mahasiswa yang diajar dengan menggunakan model pembelajaran word square berada tingkat sangat baik dengan nilai rata-rata 98.78, sementara mengidentifikasi jenis-jenis puisi yang diajar dengan menggunakan cara konvensional mendapat nilai rata-rata 79.45 dengan posisi baik sebesar $48.48 \%$.

\section{SIMPULAN}

1. Kemampuan mengidentifikasi jensi-jenis puisi oleh mahasiswa semester III program studi pendidikan bahasa dan sastra Indonesia FKIP UMSU tahun pembelajaran 20172018 jika dilihat dari nilai rata-rata mahasiswa pada kelas eksperimen yang menggunakan model pembelajaran word square adalah sebesar 98.78.

2. Kemampuan mahasiswa mengidentifikasi jenis-jenis puisi dengan menggunakan model konvensional diketahui berdasarkan nilai rata-rata hasil belajar mahasiswa pada kelas kontrol yaitu sebesar 79.45 .

3. Penelitian ini menunjukkan bahwa penggunaan model pembelajaran word square dapat mempengaruhi kemampuan mahasiswa dalam mengidentifikasi jenis-jenis puisi. Hal ini ditandai dengan nilai rata-rata yang lebih tinggi pada kelas eksperimen dan standar deviasi yang mendukung, sehingga dapat disimpulkan bahwa penggunaan model pembelajaran word square memiliki pengaruh yang nyata dan lebih baik terhadap kemampuan mengidentifikasi jenis-jenis puisi.

\section{DAFTAR PUSTAKA}

Arikunto, S. 2013. Prosedur Penelitian: suatu Pendekatan Praktis. Jakarta: Rineka Cipta.

Istarani. 2011. Metode Pembelajaran Inovatif. Medan: Media Persada.

Nurjannah, N.S. 2015. Pengaruh Model Pembelajaran Based Learning terhadap Kemampuan Menata Struktur Teks Pantun oleh Siswa Kelas XI SMK TI PAB 1 Helvetia Tahun Pembelajaran 2014-2015. Medan: FKIP UMSU.

Ruseffendi, E. T. 2005. Dasar-dasar Matematika Modern dan Komputer untuk Guru Edisi 5. Bandung: Tarsito.

Sugiyono. 2010. Metode Penelitian Pendidikan. Bandung: Alfabeta.

Umry, S.H dan Winarti. 2011. Sastra Mandiri (Telaah Puisi). Medan: Format Publishing. 